\title{
Tecnología de fabricación de filtros metálicos de bronce $^{(\bullet)}$
}

\author{
N. Krivij ${ }^{(*)}$, W. Suwardjo ${ }^{(*)}$, L. García $^{(* *)}$, A. Cores $^{(* *)}$ y A. Formoso ${ }^{(* *)}$ \\ Resumen Se han fabricado polvos esféricos de bronce, mediante la atomización del metal fundido con gas a \\ alta presión, en la instalación experimental industrial del Centro de Investigaciones Metalúrgicas \\ (CIME) de Ciudad de La Habana. Se ha realizado la caracterización físico-química y tecnológica y \\ se han determinado los parámetros óptimos para conformar y sinterizar filtros metálicos a partir de \\ estos polvos. Las propiedades mecánicas de los filtros pueden competir satisfactoriamente, en aplica- \\ ciones para equipos automotores, en la industria y en la agricultura.
}

Palabras clave: Pulvimetalurgia. Atomización. Polvo de bronce esférico. Filtros metálicos.

\section{Manufacturing method of the bronze metallic filters}

\begin{abstract}
Granulated (spherical) powders of bronze have been produced by spraying molten metal with gas at high pressure in the experimental industrial installation belonging to the Metallurgical Research Centre (CIME) in Havana City. A physical-chemical and technological characterization of the spherical bronze powder has been carried out and the optimum parameters have been determined from these powders. The mechanical properties of these filters can satisfactorily rival in applications such as in motor transport goods, in industry and agriculture.
\end{abstract}

Keywords: Powder metallurgy. Spraying molten metal. Spherical bronze powders. Metallic filters.

\section{INTRODUCCIÓN}

Para el proceso técnico son muy importantes los materiales metálicos porosos permeables sinterizados, los cuales se pueden elaborar solamente por métodos de pulvimetalurgia. Por ejemplo, la filtración fina del combustible y aceites en la actualidad es una condición necesaria para el trabajo estable en un régimen determinado de muchos motores e hidrosistemas.

En la distribución uniforme del aire o del gas, los materiales porosos permeables adquieren un gran significado.

La utilización técnica de los filtros a partir de los polvos metálicos ofrece la posibilidad de crear nuevos equipos de medición. Estos filtros se utilizan en

(•) Trabajo recibido el día 27 de junio de 1996.

(*) Centro de Investigaciones Metalúrgicas (CIME). Avda. 51, 23611, La Lisa, Ciudad de La Habana (Cuba).

(**) Unión de Empresas de Recuperación de Materias Primas. 1ra. Avenida., 1604, Miramar, Ciudad de La Habana (Cuba).

(***) Centro Nacional de Investigaciones Metalúrgicas (CENIM/CSIC). Avda. Gregorio del Amo, 8. 28040Madrid (España). varias industrias, como la petroquímica, textil, farmacéutica, alimentaria y otras. También se utilizan en el secado y purificación del aire y en la separación de mezclas de diferentes líquidos, por ejemplo, agua y aceite (1).

En las industrias química, petroquímica y de gas - se proyectan y están en explotación equipos de intercambio de calor y refrigeración. En la utilización de estos equipos, los materiales porosos permeables permiten aumentar considerablemente el coeficiente del aprovechamiento útil de estas instalaciones, así como disminuir las dimensiones del equipo para la misma potencia.

La instalación de estos materiales porosos en los omnibuses y automóviles permitirá en un futuro cercano disminuir considerablemente el consumo de combustible, el ruido y la contaminación de la atmósfera.

Actualmente, en muchas ramas de la industria, los materiales porosos permeables se utilizan en forma de bujes, conos y diferentes formas obtenidas a partir de polvos de bronce, cobre, volframio, níquel y otros materiales o aleaciones (2).

Los materiales porosos, obtenidos a partir de polvos esféricos, deben responder a requisitos de calidad determinados, entre ellos se encuentran: 
- Alta porosidad, teniendo en cuenta a la vez una resistencia mecánica aceptable. La porosidad determina la productividad de los filtros, la conductibilidad térmica, las formas y dimensiones de los poros, la fineza del filtrado; mientras que la resistencia determina las cargas mecánicas que pueden soportar los materiales porosos.

- Resistencia a la corrosión y a la formación de cascarilla mediante la utilización de materiales porosos de calidad en filtros destinados a prestar servicio en ambientes abrasivos y calientes.

- Capacidad de mantener altas propiedades de explotación en períodos largos de tiempo, fácil limpieza y regeneración, y no contaminación del medio filtrante durante el trabajo.

En este trabajo se obtiene polvo de bronce por pulvimetalurgia. Este polvo se elabora para la obtención de una serie de filtros de bronce mediante sinterización.

\section{OBTENCIÓN DEL POLVO ESFÉRICO}

Una tarea muy importante es la obtención de polvos metálicos de diferentes formas y tamaños. La forma de las partículas metálicas influye considerablemente en sus propiedades tecnológicas (3).

Los métodos actuales de obtención de polvos se dividen en dos grupos: físico-mecánicos y físicoquímicos.

Los métodos físico-mecánicos se caracterizan porque la obtención de las partículas se realiza bajo la acción de fuerzas exteriores sin que varíe sustancialmente la composición química del material. Entre estos métodos se encuentran: la trituración y molienda, y la atomización del metal fundido.

Los métodos físico-químicos se caracterizan porque la obtención de las partículas está unida al cambio de la composición química del material inicial, como resultado de profundas transformaciones físico-químicas. Este método, más universal que el físico-mecánico, permite obtener prácticamente cualquier polvo. Entre estos métodos se encuentran: reducciones de uniones químicas, electrólisis y condensación de metales.

La atomización del metal fundido es el más difundido para la obtención de polvos esféricos (46 ), con una productividad alta y pocos gastos de producción. Por este método, la atomización del metal ocurre debido a la energía cinética del gas comprimido (aire, nitrógeno, argón, etc.), proyectado bajo un determinado ángulo de impacto del chorro del líquido. Este proceso se lleva a cabo eficazmente controlando la temperatura del chorro de gas, en dependencia del tipo de polvo y su grado de esfericidad.
El proceso consiste en que el metal líquido se vierte desde el crisol de grafito hacia el colector del metal, previamente calentado a $900{ }^{\circ} \mathrm{C}$; posteriormente, el metal líquido pasa a la cámara de atomización con gas a través de un orificio en el colector.

Las partículas formadas, que tienen alta temperatura, se enfrían con agua en el momento de la caída para prevenir la unión entre ellas. El polvo, junto con el agua, se recoge en un depósito.

En la figura 1 se representa el esquema de la instalación de atomización (7).

Las partículas de polvo esféricas o redondeadas se obtienen cuando la fuerza de tensión superficial llega a dar dicha forma a las gotas de metal, antes de que éstas solidifiquen. Por ello, las partículas gruesas atomizadas tienen forma menos esférica que la finas.

El polvo de bronce ( $\mathrm{CuSn} 10 \mathrm{P} 0.3)$ con forma esférica se fabrica con la composición granulométrica que se indica en la tabla I. Esta granulometría se garantiza con la atomización del chorro de metal de 6-7 $\mathrm{mm}$ de diámetro, empleando una velocidad de

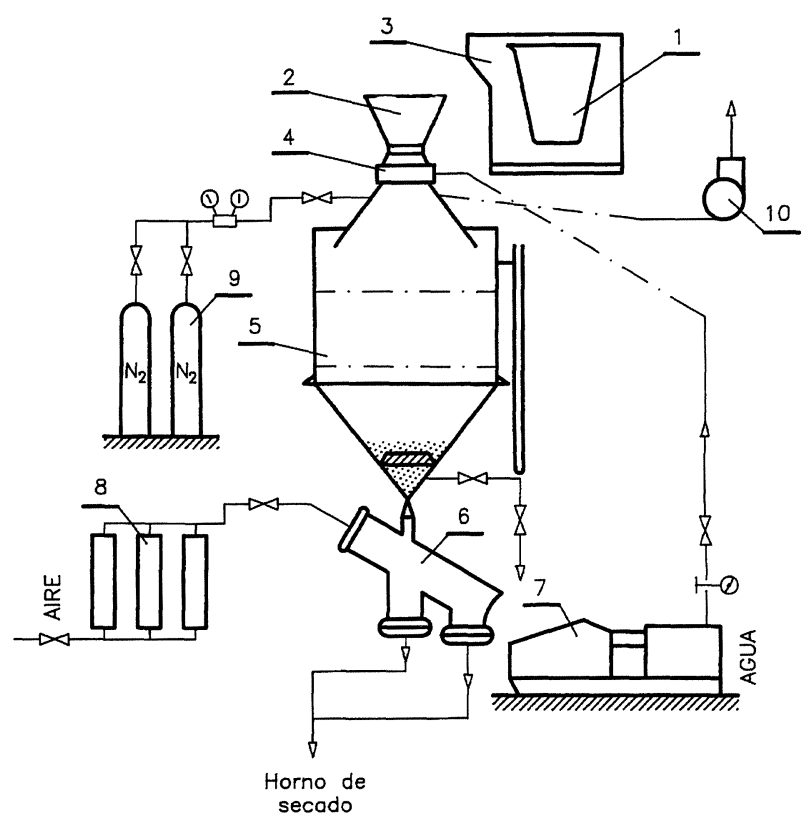

FIG. 1.- Esquema de la instalación de pulverización con agua a alta presión: 1) Crisol de grafito, 2) Colector de metal líquido, 3) Horno de inducción 4) Inyector para la pulverización, 5) Cámara de pul. verización, 6) Colector de polvos, 7) Bomba de émbolo, 8) Calentador de aire, 9) Batería de bote llas de nitrógeno, 10) Extractor.

FIG. 1.- Scheme of powdering plant with water a high pressure: 1) Graphite melting pot, 2) Collectoi liquid metal, 3) Induction furnace, 4) Powderin injector, 5) Powdering chamber, 6) Powde. collector, 7) Piston pump, 8) Blast heater 9) Battery nitrogen gas, 10) Extractor. 
TABLA I.- Distribución granulométrica del polvo de bronce $\mathrm{CuSn} 10 \mathrm{P} 0.3$, \% en masa

TABLE I.- Granulometric distribution of the bronze powder, CuSn10P0.3, \% in mass

\begin{tabular}{|c|c|}
\hline Fracción, $\mu \mathrm{m}$ & Proporción, \% \\
\hline $1000-800$ & 0,5 \\
$800-630$ & 1,5 \\
$630-400$ & 2,9 \\
$400-315$ & 2,1 \\
$315-160$ & 8,0 \\
$160-80$ & 27,0 \\
$80-63$ & 18,0 \\
$<63$ & 40,0 \\
\hline
\end{tabular}

inyección del aire en la zona de impacto de 260-280 $\mathrm{m} / \mathrm{s}$; la longitud de la zona de impacto es de 60-70 $\mathrm{mm}$, el consumo de aire de $0,8 \mathrm{~m}^{3} / \mathrm{kg}$ metal y la presión en la cámara de inyector es de 0,35-0,40 MPa.

El mecanismo y las regularidades básicas de atomización del metal fundido con el agua son idénticos a los de la atomización con gas. La diferencia más significativa consiste en la necesidad de utilizar presiones más bajas para obtener la velocidad necesaria del flujo de agua. Generalmente, la presión del chorro de agua para atomizar es de 3,5-20 $\mathrm{MPa}$. Con la atomización con agua, la mayoría de las partículas tienen forma irregular debido al enfriamiento rápido de las gotas de metal.

Disminuyendo la velocidad del flujo de agua y aumentando la temperatura del metal fundido, se pueden obtener los polvos con un contenido mayor de partículas esféricas. Después de esto, el polvo se somete a un recocido para mejorar sus propiedades.

\section{PROCESO TECNOLÓGICO PARA LA FABRICACIÓN DE POLVO DE BRONCE ESFÉRICO}

En la figura 2 se incluye el esquema tecnológico destinado a la fabricación de polvo de bronce esfé-

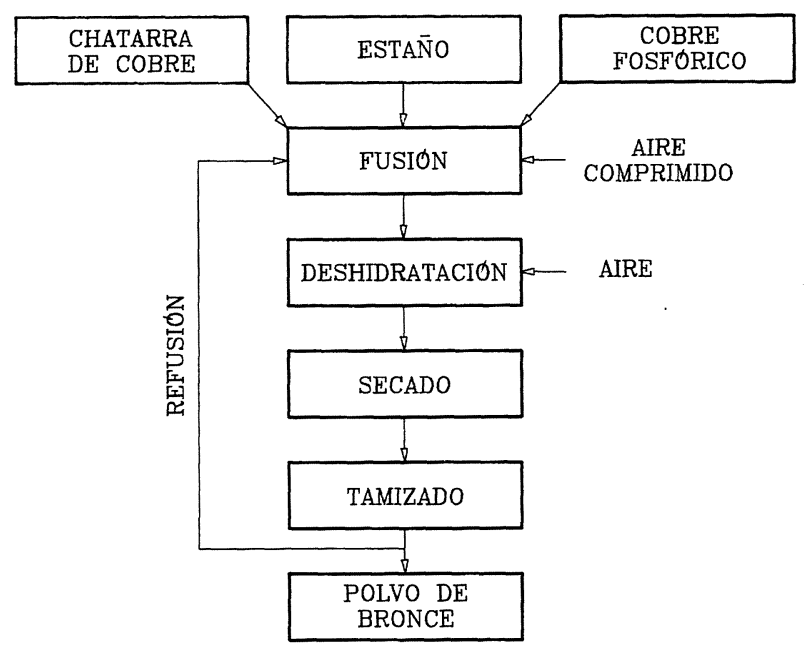

FIG. 2.- Esquema tecnológico para fabricación de polvo de bronce esférico.

FIG. 2.- Technological scheme from making spherical bronze powder.

rico, de composición CuSn10P0.3, por el método de atomización de la aleación fundida con aire comprimido en agua.

\subsection{Materiales iniciales}

En la elaboración de filtros para líquidos y gases a partir de metales no férreos, se utilizan polvos de aleaciones de cobre (2). La granulometría de estos polvos se incluye en la tabla II.

Los materiales porosos obtenidos a partir de polvo de cobre puro se utilizan poco para elaborar filtros debido a su poca resistencia a la corrosión. Se emplean en las instalaciones de intercambio de calor, ya que presentan alta conductividad térmica.

Los materiales porosos obtenidos a partir de polvo de bronce con $10 \%$ Sn y $0,1-0,3 \%$ P tienen una mayor utilización. Los filtros a partir de estos materiales resisten el calentamiento en aire hasta $200{ }^{\circ} \mathrm{C}$ y en atmósfera inerte hasta $400{ }^{\circ} \mathrm{C}(8)$.

TABLA II.- Granulometría general de los materiales base cobre para filtros

TABLE II.-General granulometrie of the copper raw materials for filters

\begin{tabular}{|l|l|l|l|l|}
\hline Denominación & Método de obtención & Forma de partículas & Granulometría & Composición química \\
\hline $\begin{array}{l}\text { Polvo de bronce } \\
\text { pulverizado }\end{array}$ & $\begin{array}{l}\text { Atomización con } \\
\text { aire en aire }\end{array}$ & $\begin{array}{l}\text { Esférica o no } \\
\text { esférica }\end{array}$ & $85 \%<160 \mu \mathrm{m}$ & $99 \% \mathrm{Cu}$ \\
\hline $\begin{array}{l}\text { Polvo de bronce } \\
\text { al estaño CuSn10 }\end{array}$ & $\begin{array}{l}\text { Atomización con } \\
\text { aire en agua }\end{array}$ & Esférica & $\begin{array}{l}100 \% \text { entre } 40 \\
\text { y } 400 \mu \mathrm{m}\end{array}$ & $\begin{array}{l}10 \% \mathrm{Sn} \\
\text { Base Cu }\end{array}$ \\
\hline $\begin{array}{l}\text { Polvo de bronce } \\
\text { al estaño y } \\
\text { fósforo CuSn10P0.3 }\end{array}$ & $\begin{array}{l}\text { Atomización con } \\
\text { aire en agua }\end{array}$ & Esférica & $\begin{array}{l}100 \% \text { entre } 50 \\
\text { y } 450 \mu \mathrm{m}\end{array}$ & $\begin{array}{l}10 \% \mathrm{Sn} \\
\text { Base Cu } \\
0,1-0,3 \% \mathrm{P}\end{array}$ \\
\hline
\end{tabular}


El contenido de fósforo, que influye favorablemente en la sinterización, es de hasta $0,3 \%$; contenidos más elevados tienen una influencia perjudicial; por ejemplo, con $0,5 \%$ se forman grietas como consecuencia de grandes contracciones y con $0,7 \%$ se forma fase líquida que cierra los poros y fragiliza el material del filtro.

La chatarra de cobre de primera se utiliza en forma de placas compactas que no excedan las dimensiones del crisol de grafito $(180 \mathrm{~mm}$ de diámetro y $400 \mathrm{~mm}$ de profundidad) del horno de inducción donde se efectúa la fusión. Esta chatarra no debe presentar inclusiones extrañas, y en el caso de cables eléctricos deben estar sin la cubierta protectora.

Los lingotes de estaño se cortan con un peso inferior a los de carga. El cobre con contenido de fósforo se emplea en forma de pastilla.

Los componentes de la carga deben pesarse en las proporciones siguientes:

- chatarra de cobre $=70 \mathrm{~kg}$;

- estaño $=7 \mathrm{~kg}$;

- pastillas de cobre con fósforo $=3 \mathrm{~kg}$.

Como protección del metal líquido contra la oxidación atmosférica durante la fusión, se utiliza carbón vegetal de fracción inferior a $20 \mathrm{~mm}$.

\subsection{Fusión de la carga}

La fusión de la carga se realiza en el horno de inducción con crisol de grafito. En el fondo del crisol, previamente limpio de residuos de anteriores fusiones, se deposita carbón vegetal de 10-20 mm en cantidad tal que cubra la superficie del baño metálico. Después, se carga la chatarra de cobre y se enciende el horno. Una vez fundido, el cobre se desoxida con $3 \mathrm{~kg}$ de pastillas de cobre con fósforo y se agrega el estaño, agitando constantemente el baño metálico hasta lograr la disolución completa del estaño en el cobre fundido. Antes de ser vertido en el depósito receptor del metal para su atomización, se eleva la temperatura de la aleación hasta $1.200-1.250{ }^{\circ} \mathrm{C}$ y se limpia la superficie del baño metálico de cualquier suciedad. La temperatura se controla con un termopar de inmersión.

\subsection{Atomización de la aleación}

Antes del comienzo de la atomización hay que cerciorarse de que la rampa de balones de aire haya sido cargada mediante el compresor hasta una presión de $10 \mathrm{MPa}$. Se ajusta el área de salida de los chorros del inyector y se fija el mismo en la zona de atomización. Se prepara el receptor de metal para su trabajo fijándolo con silicato de sodio a la tobera de salida del metal con un diámetro entre 6-7 $\mathrm{mm}$ y se coloca encima del inyector de gas. Se debe comprobar que la tobera de salida del metal esté centrada entre las cámaras del inyector, y mediante un quemador se calienta el receptor hasta una temperatura cercana a $900{ }^{\circ} \mathrm{C}$. El metal previamente recalentado y limpio de cualquier impureza se vierte paulatinamente en el receptor de metal cuidando de mantener una columna de metal en el mismo de aproximadamente $150 \mathrm{~mm}$.

Antes de verter el metal en el depósito receptor se suministra aire comprimido a la cámara de los inyectores. La presión se controla constantemente mediante un manómetro y se regula con la válvula colocada en el distribuidor de aire. La presión se regula de acuerdo con el tamaño medio de las partículas a obtener, en tanto que el área de salida de los chorros del inyector se regula para un caudal de aire del orden de $0,2-0,3 \mathrm{~kg} / \mathrm{kg}$ metal o de $0,25-4,0$ $\mathrm{m}^{3} / \mathrm{kg}$ metal.

La temperatura del metal se controla con un termopar de inmersión o un pirómetro óptico. Las temperaturas de las últimas porciones de metal no deben ser inferiores a $1.050{ }^{\circ} \mathrm{C}$.

\subsection{Secado y clasificación del polvo}

La mayor parte del agua que contiene el polvo sedimentado en la cámara de atomización, se elimina mediante aire a una presión de 0,5 $\mathrm{MPa}$. El agua que se extrae de esta etapa se recicla a la cámara de atomización.

El polvo húmedo se extrae del colector de polvo, se coloca en bandejas y se seca a una temperatura de $80-100{ }^{\circ} \mathrm{C}$.

El polvo se clasifica según la granulometría deseada. Las fracciones superiores e inferiores a la requerida se recirculan de nuevo para su fusión. La composición granulométrica se determina según la Norma ISO 4497.

La forma de las partículas influye en la densidad aparente del polvo, en su comportamiento al prensado, conformación, resistencia y uniformidad de las piezas compactadas. La mayor resistencia de los compactos se obtiene con el polvo de forma dentrítica.

Los polvos metálicos, en dependencia del método empleado en su elaboración, tendrán una composición granulométrica determinada, siendo los métodos de reducción y electrólisis los que dan un mayor intervalo de dimensiones. La composición granulométrica se determina por tamizado, observación al microscopio, sedimentación u otras técnicas, de acuerdo a las dimensiones de las partículas. Para partículas entre 1 y $100 \mu \mathrm{m}$, se utiliza el microscopio óptico, y para partículas $<1 \mu \mathrm{m}$ el microscopio 
electrónico. La sedimentación se utiliza para partículas entre $0,4-0,5 \mu \mathrm{m}$.

\subsection{Propiedades tecnológicas}

Entre las propiedades tecnológicas que debe satisfacer el polvo elaborado se encuentran la fluidez y la densidad aparente.

La fluidez se determina por el tiempo requerido para el paso de $50 \mathrm{~g}$ de polvo metálico que fluye a través de un embudo calibrado de dimensiones estandarizadas. La determinación de la fluidez se realiza según la Norma ISO 4490.

La densidad aparente es la cantidad de masa por unidad de volumen de los polvos obtenidos mediante la caída libre de los mismos. En la densidad aparente influye la forma y el tamaño de las partículas. Esta característica, a su vez, influye en los cálculos para la fabricación de los moldes de las piezas. La densidad aparente se determina según las Normas ISO 3923/1 y 3923/2. Las propiedades del polvo de bronce CuSn10P0.3 obtenido en este trabajo se incluyen en la tabla III.

\section{TECNOLOGÍA DE ELABORACIÓN DEL FILTRO}

En la figura 3 se incluye el esquema tecnológico para la fabricación del filtro (9 y 10).

La preparación de los polvos incluye los métodos tradicionales empleados en pulvimetalurgia (tamizado y recocido) y métodos característicos de la fabricación de materiales porosos metálicos (esferoidización y granulado de partículas, separación de las partículas esféricas).

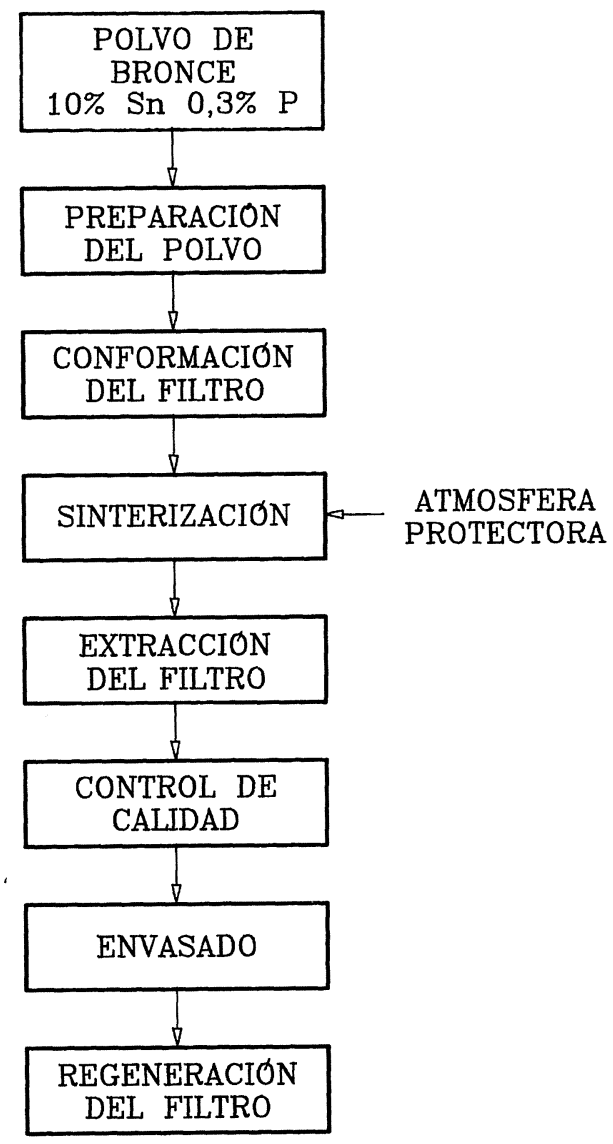

FIG. 3.- Esquema tecnológico para la elaboración de los filtros.

FIG. 3._- Technological scheme from making filters.

\subsection{Formación de los filtros}

La formación consiste en dar la forma, dimensiones, densidades y propiedades mecánicas para

TABLA III.- Propiedades del polvo de bronce CuSn10P0.3

TABLE III.- Properties of the bronze powder CuSn10P0.3

\begin{tabular}{|c|c|c|c|c|c|}
\hline$d_{\text {part. }}, \mu \mathrm{m}$ & Factor de forma & $\begin{array}{c}\text { Densidad pignométrica, } \\
\mathrm{g} / \mathrm{cm}^{3}\end{array}$ & $\begin{array}{c}\text { Densidad } \\
\text { aparente, } \mathrm{g} / \mathrm{cm}^{3}\end{array}$ & $\begin{array}{c}\text { Dens. después } \\
\text { de vibrado, } \mathrm{g} / \mathrm{cm}^{3}\end{array}$ & $\begin{array}{c}\text { Fluidez, } \\
\mathrm{s} / 50 \mathrm{~g}\end{array}$ \\
\hline $1000-800$ & 0,94 & 8,78 & 5,16 & 5,57 & - \\
$800-630$ & 0,95 & 8,49 & 5,20 & 5,66 & 26,2 \\
$630-400$ & 0,95 & 8,80 & 5,23 & 5,68 & 22,2 \\
$400-315$ & 0,96 & 8,80 & 5,32 & 5,75 & 19,6 \\
$315-160$ & 0,90 & 8,78 & 4,95 & 5,50 & 18,8 \\
$160-80$ & 0,92 & 8,79 & 5,03 & 5,57 & 16,2 \\
$80-63$ & 0,93 & 8,79 & 5,05 & 5,67 & 15,0 \\
$<63$ & 0,93 & 8,80 & 5,20 & 5,70 & 13,8 \\
\hline
\end{tabular}


los procesos de obtención de materiales porosos metálicos que se incluyen en la figura 4.

El prensado se utiliza para la fabricación de artículos de forma sencilla (discos, conos, cilindros). Este método tiene varias desventajas como son las limitaciones en cuanto a la forma y tamaño de los filtros y la distribución no uniforme de la porosidad, debido a la fuerza de fricción que surge entre las partículas de polvo y entre éstas y las paredes del molde. El prensado conduce a la distribución no uniforme de la porosidad y de las dimensiones de los poros en el filtro elaborado. Entre las ventajas de este método se encuentran la gran exactitud de dimensiones y la alta productividad.

El laminado de los polvos consiste en la formación continua de una cinta porosa mediante rodillos. Se realiza en un laminador por diferentes métodos que se diferencian entre sí por la situación de las coordenadas de los rodillos. Las ventajas principales del laminado consisten en la posibilidad de fabricación de materiales porosos en forma de cintas finas de $550 \mathrm{~mm}$ de ancho y $5 \mathrm{~mm}$ de espesor con porosidad entre 20-30 \%. Las desventajas consisten en la forma simple y la baja resistencia de los materiales porosos metálicos que se obtienen.

El llenado libre de los polvos en un molde es el método más sencillo de formación de los materiales porosos metálicos sin aplicación de la presión. Para mejorar el llenado de los moldes con el polvo y obtener materiales porosos metálicos con una porosidad uniforme, el molde, durante el llenado, se somete a vibraciones (manualmente o en electrovibrador). En la porosidad final del polvo ejerce una influencia considerable la aceleración, la frecuencia de vibración (Tabla IV) y la velocidad de llenado del molde.

La forma y el tamaño de los filtros formados mediante el llenado libre solamente están limitados por el espacio de trabajo del horno de sinterización.

\subsection{Conformación del filtro}

En la conformación del filtro se utiliza el método de llenado libre de los polvos esféricos en el

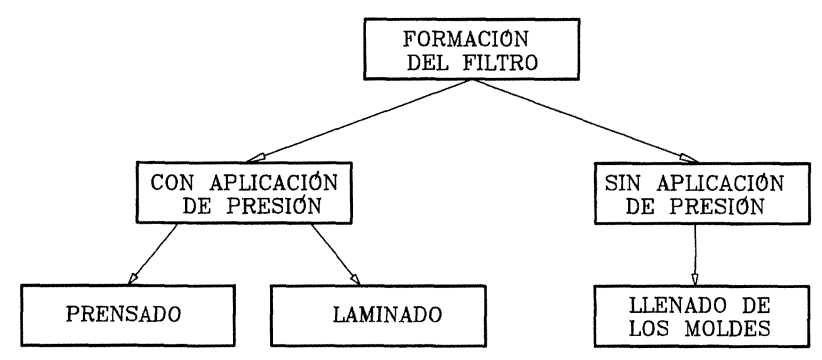

FIG. 4.- Esquema de la conformación de los filtros.

FIG. 4.- Scheme of the filters formation.
TABLA IV.- Influencia de la aceleración y la frecuencia de vibración en la porosidad

TABLE IV.- Effect of the acceleration and vibration frequency in the porosity

\begin{tabular}{|c|c|c|c|}
\hline \multirow[b]{2}{*}{$d_{\mathrm{p}}, \mu \mathrm{m}$} & \multicolumn{2}{|c|}{ Parámetros de vibración } & \multirow[b]{2}{*}{$P$} \\
\hline & $\begin{array}{c}\text { Aceleración, } \\
\mathrm{m} / \mathrm{s}^{2}\end{array}$ & $\begin{array}{c}\text { Frecuencia, } \\
\mathrm{Hz}\end{array}$ & \\
\hline 63 & $\begin{array}{l}1,67 \\
1,89 \\
2,73 \\
2,61\end{array}$ & $\begin{array}{r}20 \\
50 \\
100 \\
200\end{array}$ & $\begin{array}{l}0,495 \\
0,479 \\
0,469 \\
0,471\end{array}$ \\
\hline 315 & $\begin{array}{l}1,67 \\
1,89 \\
2,73 \\
2,61\end{array}$ & $\begin{array}{r}20 \\
50 \\
100 \\
200\end{array}$ & $\begin{array}{l}0,538 \\
0,573 \\
0,508 \\
0,514\end{array}$ \\
\hline 630 & $\begin{array}{l}1,41 \\
2,73 \\
2,67\end{array}$ & $\begin{array}{r}50 \\
100 \\
200\end{array}$ & $\begin{array}{l}0,530 \\
0,521 \\
0,527\end{array}$ \\
\hline
\end{tabular}

molde por ser este el más simple para la formación de piezas porosas sin aplicación de presión. Para el mejor llenado del molde con el polvo y la obtención de piezas con porosidad uniforme, el molde durante el llenado se somete a vibración mecánica. Este método tiene poca productividad, pero ofrece la posibilidad de obtener piezas de forma compleja con sencillez en su operación.

La formación de los filtros por este método, utilizando polvos de diferentes tamaños de partículas con forma esférica, permite obtener la porosidad de $25-50 \%$ en los filtros sinterizados (11).

\subsection{Preparación y llenado de los moldes}

En esta operación se realiza la limpieza y el revestimiento de los moldes para lograr la eliminación de óxidos y restos de materia en el cuerpo, matriz y tapa del molde. El revestimiento del molde tiene como finalidad que las partículas de polvo no se adhieran a las paredes del mismo durante la sinterización. Para el revestimiento se utiliza una disolución de alcohol polivinílico. Toda la superficie interior del molde se recubre de una película de esta disolución y, posteriormente, se añade sobre el alcohol una capa delgada de polvo ultrafino de óxido de aluminio.

Con objeto de que el llenado de los moldes sea lo más homogéneo posible, se realiza utilizando un vibrador mecánico. El polvo se va añadiendo paulatinamente en el molde que se encuentra vibrando constantemente hasta que el mismo esté completamente lleno; se enrasa y se ajusta. 
El molde para la fabricación del filtro consta de tres piezas de acero Cr12Mn. El diseño del molde se realiza tomando en consideración la contracción del material del filtro en el momento de ser sinterizado.

\section{SINTERIZACIÓN DEL FILTRO}

La sinterización es el proceso de desarrollo de los enlaces interpartículas y la formación de las propiedades del material. Mediante este proceso se convierte el comprimido o el polvo vertido libremente en un cuerpo sinterizado, resistente, con propiedades cercanas a los cuerpos compactos (12).

Las propiedades finales de los materiales porosos se establecen con la sinterización, cuyo objetivo principal es el aumento de la resistencia del filtro con la conservación de la porosidad correspondiente (11).

La sinterización del filtro es un tratamiento térmico de los polvos iniciales a una temperatura más baja que la temperatura de fusión del componente base y se produce en tres etapas. En la etapa inicial, las partículas se adhieren entre sí, aumentando la superficie de contacto entre ellas y acercándose a los centros debido a la difusión que ocurre en los lugares de contacto entre las mismas. En la segunda etapa, el cuerpo poroso se puede representar en forma de unión de dos fases que penetran una en la otra (fase de sustancias y fase de vacío). En la etapa final, el cuerpo poroso tiene los poros aislados y su consolidación ocurre con disminuciones de la cantidad y del volumen de los poros del filtro (2 y 13).

En la sinterización de los filtros la etapa inicial se caracteriza por la formación de enlaces entre las partículas y por el incremento de los contactos entre ellas. Esto ocurre en lugares donde existe un contacto físico entre las partículas. En esta etapa no se observan deformaciones dimensionales del filtro, y en él ocurren transformaciones importantes que provocan, ante todo, el aumento de la resistencia. En los cuerpos porosos, a partir del polvo esférico, el contacto metálico representa una parte pequeña de la superficie del polvo. En la sinterización aumentan los contactos entre las partículas y se mejoran las propiedades mecánicas del metal en el lugar de contacto.

Se debe destacar que en la producción de filtros la sinterización se puede terminar en esta etapa, y este principio es utilizado para elaborar diferentes tipos de filtros presentados en este trabajo.

El endurecimiento del material como resultado de la sinterización depende de la temperatura y el tiempo de retención.

Los filtros de partículas esféricas de bronce, en dependencia del tamaño de la partícula, se sinterizan a $750-870{ }^{\circ} \mathrm{C}$ durante $30-60 \mathrm{~min}$. Los filtros elaborados por llenado libre, se sinterizan junto con el molde en atmósfera reductora de hidrógeno. Después del enfriamiento en atmósfera de nitrógeno, los filtros se extraen del molde fácilmente.

En la tabla V se incluye el régimen de temperaturas de sinterización para diferentes tamaños de las partículas esféricas de polvo de bronce esférico CuSn10P0.3.

En cuanto al cambio de la porosidad y a la contracción del filtro, en dependencia de la temperatura de sinterización, se determina que estas características no presentan cambios significativos. Con una temperatura alta se disminuye la porosidad considerablemente, lo que está relacionado con la fusión de los contactos entre partículas.

El estudio de la influencia del tiempo de retención en las propiedades físico-mecánicas de los filtros muestra que prácticamente no influye en la porosidad y resistencia dentro del intervalo señalado en todas las dimensiones de las partículas del polvo. Se ha logrado una mejora de la resistencia con el tiempo debido a una pequeña disminución de la porosidad (9).

En cuanto a la influencia de la temperatura de sinterización en las propiedades mecánicas hay que señalar que en el intervalo de $780-860{ }^{\circ} \mathrm{C}$ todas las propiedades mecánicas no presentan cambios significativos. Con la temperatura de sinterización más baja, las propiedades de resistencia y plasticidad disminuyen considerablemente, debido a la disminución del área de contacto entre las partículas. Con temperaturas $>860^{\circ} \mathrm{C}$, las propiedades mecánicas aumentan bruscamente debido a una disminución de la porosidad.

Las propiedades mecánicas de los filtros elaborados a partir de polvo esférico de bronce,

TABLA V.- Régimen de temperatura en dependencia del tamaño de partículas

TABLE V.- Temperature condition in the dependence with size particles

\begin{tabular}{|c|c|}
\hline $\begin{array}{c}\text { Tamaño de las partículas } \\
\text { del polvo, } \mu \mathrm{m}\end{array}$ & $\begin{array}{c}\text { Temperatura } \\
\text { de sinterización, }{ }^{\circ} \mathrm{C}\end{array}$ \\
\hline $63-50$ & $750-760$ \\
$80-63$ & $760-770$ \\
$100-80$ & $770-780$ \\
$125-100$ & $775-785$ \\
$160-125$ & $785-795$ \\
$200-160$ & $795-805$ \\
$250-200$ & $805-815$ \\
$315-250$ & $815-825$ \\
$400-315$ & $825-835$ \\
$500-400$ & $835-875$ \\
$630-500$ & $855-875$ \\
$800-630$ & $855-865$ \\
$1.000-800$ & $865-875$ \\
\hline
\end{tabular}


dependen del tamaño de las partículas; con el bronce más fino (por ej., 200-250 $\mu \mathrm{m}$ en comparación con 400-500 $\mu \mathrm{m}$ ), las propiedades mecánicas son más altas, ya que disminuye la porosidad general y aumenta la cantidad de contactos entre las partículas.

En el presente trabajo la sinterización se realiza en un horno mufla de laboratorio, en atmósfera controlada de amoníaco disociado (75\% de hidrógeno y $25 \%$ de nitrógeno). Durante este proceso se obtienen las propiedades finales de los filtros.

La extracción de los filtros se realiza de forma manual quitando la tapa al molde.

Los parámetros a controlar en el filtro terminado son:

- buen aspecto superficial,

- buena soldabilidad entre partículas,

- porosidad uniforme,

- ausencia de fusiones (fundidos).

En los filtros terminados se determina el tamaño de los poros en muestras sinterizadas a diferentes temperaturas, a tal efecto se emplea un microscopio óptico NEOPHOT 30; se realizan 100 mediciones para cada filtro.

La determinación de la porosidad se realiza por el método hidrostático.

En la figura 5 se pueden observar algunos de los filtros de bronce fabricados. El A es un filtro de agua, de tamaño de partículas de polvo entre 800-1.000 $\mu \mathrm{m}$, que se utiliza en máquinas de riego. El B es un filtro de queroseno, de tamaño de partículas de 630-800 $\mu \mathrm{m}$, utilizado en cocinas. El C es un filtro de aceite, de tamaño de partículas de 400-630 $\mu \mathrm{m}$, para sistemas mecánicos de compresores. El D es un filtro de aire, vapor y agua, tamaño de partículas de $80-125 \mu \mathrm{m}$, que se utiliza en los sistemas de abastecimiento de los equipos de fermentación.

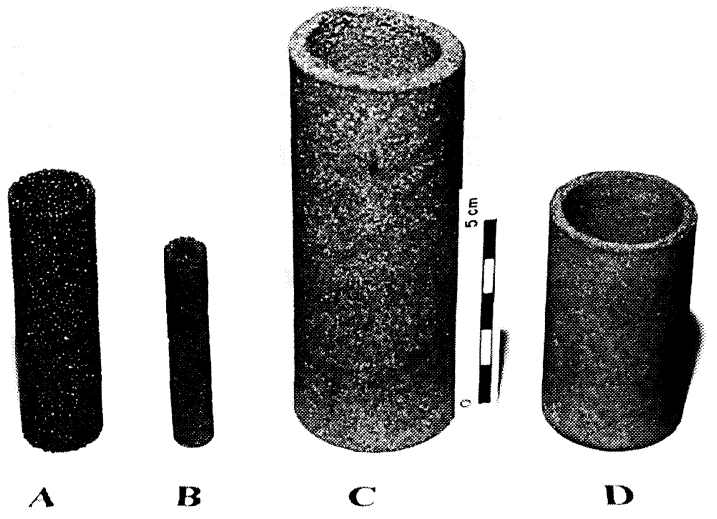

FIG. 5.- Filtros de bronce.

FIG. 5.-Bronze filters.
Las propiedades finales de estos filtros se inclu. yen en la tabla VI.

\subsection{Análisis de los filtros mediante MEB}

Se ha estudiado la estructura de los filtros de bronce $\mathrm{B}$ y $\mathrm{D}$ en un microscopio electrónico de barrido con microsonda JEOL modelo JSM-840, dotado con un analizador LINK AN-10.000.

En la tabla VII se ofrece el análisis de cada filtro, siendo el cobre y el estaño los únicos elementos detectados en el espectro realizado.

La figura 6 corresponde a una zona de la sección transversal del filtro $\mathrm{B}$, formada por esferas de bronce y con presencia de porosidad. En la figura 7 se muestra en detalle una zona localizada en la figura anterior, donde se puede observar la unión de dos esferas de estructura densa.

La figura 8 corresponde a una zona de la sección transversal del filtro $\mathrm{D}$, formada por esferas de bronce más pequeñas que las del filtro $\mathrm{B}$, y con presencia de porosidad. La figura 9 ofrece detalle de una zona localizada en la figura anterior formada por esferas de estructura densa.

TABla VI.- Propiedades de los filtros a partir de polvo de bronce esférico CuSn10P0.3 con diferentes granulometrías

TABLE VI.- Filters properties of spherical bronze powder CuSn10P0.3 with different granulometries

\begin{tabular}{|c|c|r|r|r|}
\hline \multirow{2}{*}{$\begin{array}{c}\text { Diámetro } \\
\text { de partícula, } \\
\mu \mathrm{m}\end{array}$} & & \multicolumn{3}{|c|}{$\begin{array}{r}\text { Diámetro del poro, } \\
\mu \mathrm{m}\end{array}$} \\
\cline { 3 - 4 } & Porosidad & Máximo & Medio & \multirow{2}{*}{$A_{\text {nom. } \mu \mathrm{m}}$} \\
\hline $1.000-800$ & 0,42 & 360 & 230 & $115-125$ \\
$800-630$ & 0,41 & 240 & 195 & $100-110$ \\
$630-500$ & 0,40 & 200 & 161 & $75-85$ \\
$500-400$ & 0,39 & 185 & 117 & $50-65$ \\
$400-315$ & 0,38 & 140 & 92 & $35-45$ \\
$315-250$ & 0,37 & 95 & 59 & $25-35$ \\
$250-200$ & 0,35 & 75 & 43 & $20-25$ \\
$200-160$ & 0,33 & 65 & 33 & $15-18$ \\
$160-125$ & 0,32 & 52 & 30 & $10-14$ \\
$125-80$ & 0,30 & 31 & 16 & $7-9$ \\
\hline
\end{tabular}

$A_{\text {nom }}=$ fineza de filtración nominal

TABLA VII.- Análisis químico puntual de los filtros, $\%$ en masa

TABLE VII.- Point chemical analysis of the filters, $\%$ in mass

\begin{tabular}{|c|c|c|}
\hline Filtro & $\mathrm{Cu}$ & $\mathrm{Sn}$ \\
\hline $\mathrm{B}$ & 85,72 & 8,54 \\
$\mathrm{D}$ & 92,44 & 7,46 \\
\hline
\end{tabular}




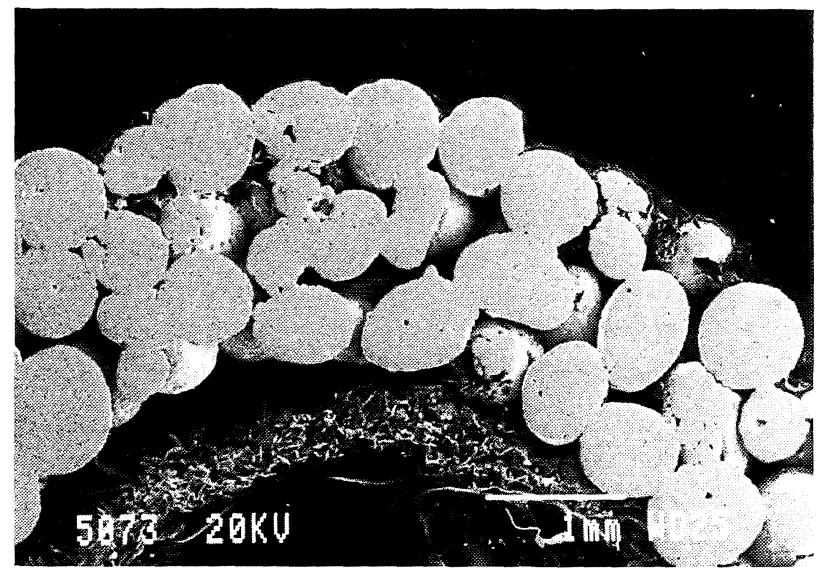

FIG. 6.- Sección transversal del filtro B. Presencia de esferas y porosidad $(\times 20)$.

FIG. 6.- Transversal section of filter B. Presence of spheres and porosity $(\times 20)$.

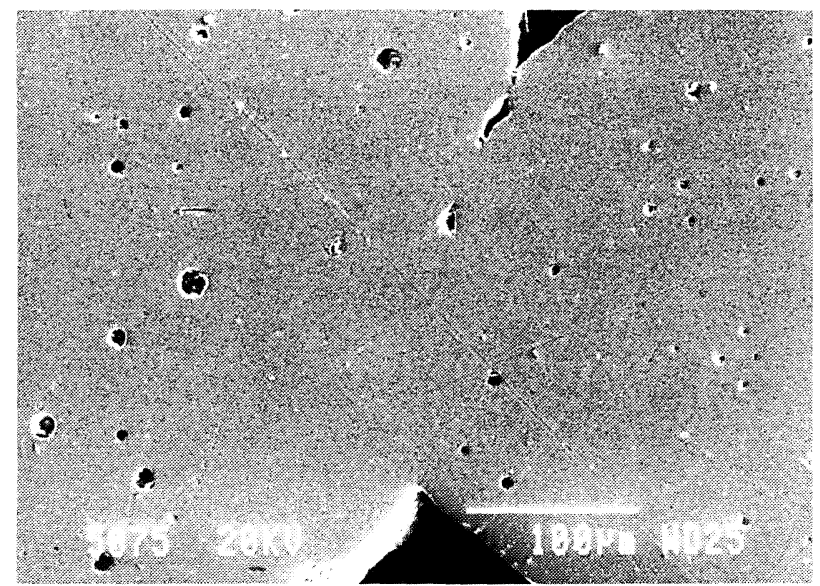

Fig. 7.- Zona de detalle localizada en la figura 6 $(\times 250)$.

FIG. 7.-Detail of zone from figure 6. $(\times 250)$.

\section{REGENERACIÓN DE LOS FILTROS}

Durante su utilización, los filtros se tupen, lo que ocasiona que su permeabilidad disminuya llegando un momento en que el filtro no deja pasar el medio filtrante; con esto surge la necesidad de cambio. Sin embargo, en la práctica, la sustitución muy frecuente de los filtros tupidos por nuevos no siempre es posible ni cómoda, además esto también implica el aumento del costo. Por eso, el aumento de la vida útil de los filtros, por vía de la regeneración, es una tarea muy importante.

Para restablecer la capacidad filtrante del filtro es necesario eliminar periódicamente todo el sedimento que se forma en la superficie del mismo y limpiar los poros. Existen varios métodos, entre ellos:

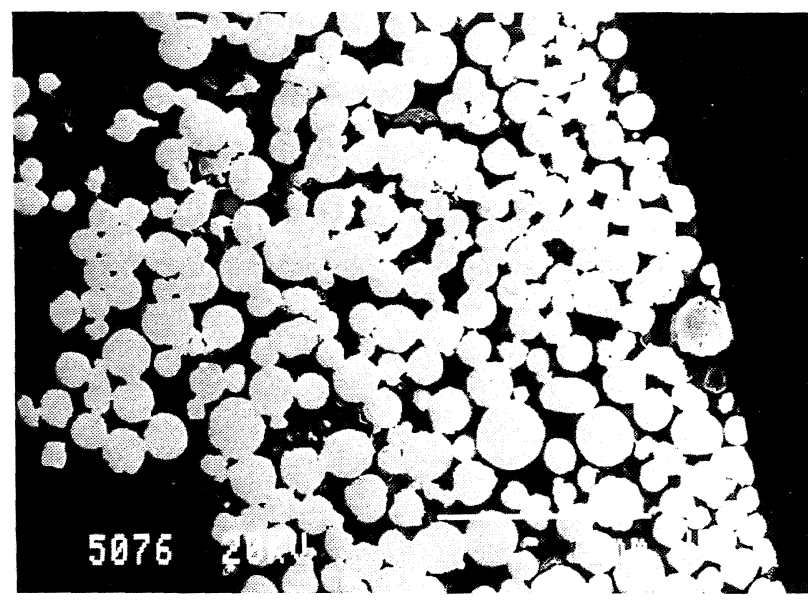

FIG. 8.- Sección tranasversal del filtro D. Presencia de esferas y porosidad $(\times 30)$.

FIG. 8.- Transversal section of filter D. Presence of spheres and porosity $(\times 30)$.

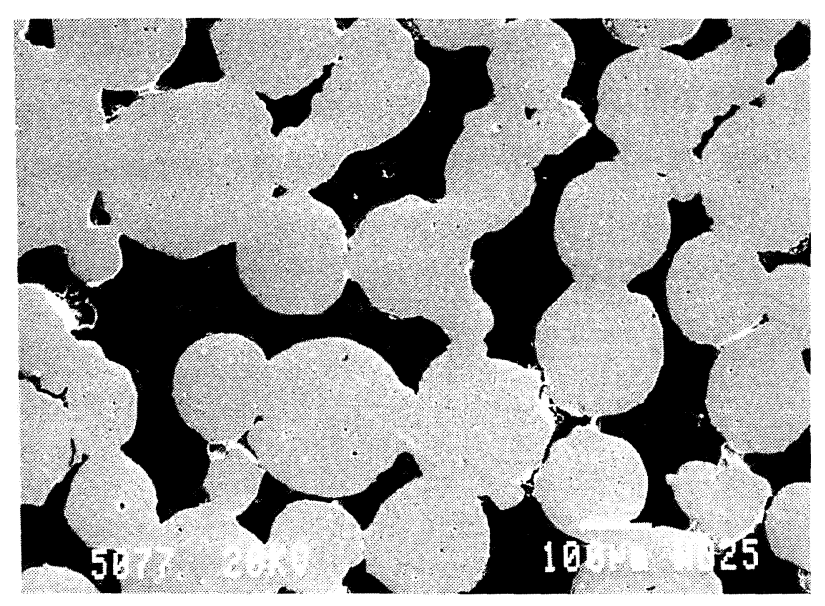

FIG. 9.-Zona en detalle del centro localizada en la figura $8(\times 100)$.

FIG. 9.- Central detail of zone from figure $8(\times 100)$.

- Limpieza mecánica a contrapresión. Con este método de limpieza, el medio filtrante pasa por el filtro en dirección contraria a la del filtrado. La limpieza se realiza en condiciones de sobrepresión en 4,9-9,8 $\times 10^{5} \mathrm{~N} / \mathrm{m}^{2}$ superior a la presión del filtrado. Este método es el más sencillo y cómodo, realizándose sin perjuicio o desventajas de los elementos filtrantes. En la mayoría de los casos, la contrapresión se realiza con el mismo medio filtrante, que ha sido filtrado anteriormente. Mediante este procedimiento los filtros se pueden regenerar de 4 a 5 veces.

- Limpieza química mediante disolventes. Los disolventes pasan a través del filtro en sentido contrario. Este método no siempre se puede utilizar, debido a que los elementos filtrantes pueden estar elaborados de un material que reacciona con los disolventes. 
- Limpieza térmica. Consiste en calentar el filtro en un chorro de gas caliente, con lo que se queman las impurezas incrustadas.

\section{CONCLUSIONES}

En este trabajo se proyectaron y elaboraron diferentes tipos de filtros, utilizados en varias ramas de la industria cubana, a partir de polvo esférico de bronce $\mathrm{CuSn} 10 \mathrm{P} 0.3$ de diferentes granulometrías, mediante métodos usualmente empleados en Pulvimetalurgia. Estos son:

- Filtros de aire, vapor y agua de los sistemas de alimentación de equipos de fermentación con tamaño de partículas de polvo de 80-125 $\mu \mathrm{m}$.

- Filtro para aceite en los sistemas mecánicos de los compresores con tamaño de partículas de polvo de $400-630 \mu \mathrm{m}$.

- Filtros para cocinas de queroseno (domésticas y comerciales) con tamaño de partículas de polvo de $630-800 \mu \mathrm{m}$.

- Filtro de agua para máquinas de riego con tamaño de partículas de polvo de $800-1.000 \mu \mathrm{m}$.

Se destaca que los materiales y recursos empleados en la elaboración de estos filtros son de procedencia nacional, siendo muy halagüenas las expectativas de los mismos en cuanto a costos de producción en caso de materializarse a mayores escalas de producción fuera de los limites de laboratorio.

\section{REFERENCIAS}

(1) Paulovskayn, E.I. Los filtros metalocerámicos. Ed. Moscú, "Metallurgiya", 1967: 172 p., en ruso.

(2) Belov, S.V. Materiales porosos permeables. Ed. Moscú, "Metallurgiya", 1987: 231 p., en ruso.

(3) KRIVIJ, N. Estudio de la nomenclatura y factibilidad técnico-económica de la obtención de diferentes tipos de filtros para la economía a partir de diferentes aleaciones. Informe Técnico CIME, Ed. CIME, Ciudad de La Habana, 1990: $113 \mathrm{p}$.

(4) Belyakov, V.A., Medvedovsky, A.B., Nichiporenko, O.S., Poteshkina, V.P., NAida, Yu.I. y PotasheVa, G.A. Poroshk. Metal., (69), 1981: 13-15.

(5) Krivij, N., Suwardjo, W. y Cores, A. Rev. Metal. Madrid, 31 (6), 1995: 394-399.

(6) Krivis, N., Suwardjo, W., Frades, J., Chacon, T., Cores, A. y Garcia, L. Rev. Metal. Madrid, 32 (6), 1996: 391-396.

(7) Suwardjo, W. y Krivij, N. Bol. ICT. CIME/SIME, Año X (2), 1989: 17-31.

(8) Suwardjo, W., KriviJ, N. y Frades, J. Proc. X Seminario - CNIC, La Habana, Vol. I, 1980: 551-560.

(9) KRIVIJ, N. Filtro para el camión ZIL. Informe Técnico CIME. Ed. CIME, Ciudad de La Habana, 1990: 67 p.

(10) Krivis, N. Producción experimental del filtro para la máquina de riego Fregat. Valoración técnico-económica. Informe Técnico CIME, Ed. CIME, Ciudad de La Habana, 1989: $55 \mathrm{p}$.

(11) Stepanchuk, A.N. Tecnología de la metalurgia de polvos. Ed. Kiev, "Nauka", 1989: 105 p., en ruso.

(12) Molera, O. Introducción a la pulvimetalurgia. Ed. España, "Bellaterra, S.A.", 1977: 231 p.

(13) Shibryaev, B.F. Materiales porosos permeables sinterizados. Ed. Moscú, "Metallurgiya", 1983: 187 p., en ruso. 